\title{
Soil Clinics: Farmers Teaching Smart-Farming to Farmers
}

\section{A. Wongmaneeroj ${ }^{1}$, R. Pitakdantham ${ }^{2}$, S. Thawornpruek ${ }^{2}$, P. Verapattananirund ${ }^{3}$, R. S. Yost ${ }^{4}$, T. Attanandana ${ }^{2}$}

${ }^{1}$ Department of Soil Science, Kasetsart University, Nakhon Pathom, Thailand

${ }^{2}$ Department of Soil Science, Kasetsart University, Bangkok, Thailand

${ }^{3}$ Eco-Community Vigor Foundation, Bangkok, Thailand

${ }^{4}$ Department of Tropical Plant and Soil Sciences, University of Hawaii at Manoa, Honolulu, USA

Email: rsyost@hawaii.edu

How to cite this paper: Wongmaneeroj, A., Pitakdantham, R., Thawornpruek, S., Verapattananirund, P., Yost, R.S. and Attanandana, T. (2019) Soil Clinics: Farmers Teaching Smart-Farming to Farmers. Agricultural Sciences, 10, 1194-1205. https://doi.org/10.4236/as.2019.109089

\section{Received: July 10, 2019}

Accepted: September 23, 2019

Published: September 26, 2019

Copyright $\odot 2019$ by author(s) and Scientific Research Publishing Inc. This work is licensed under the Creative Commons Attribution International License (CC BY 4.0).

http://creativecommons.org/licenses/by/4.0/

\section{cc) (i) Open Access}

\begin{abstract}
In Thailand, the site-specific nutrient management technology, known as "Tailor-made Fertilizer Technology (TFT)", for rice, maize and sugarcane in the Northeastern region was developed between 1997-2007, using the concepts of precision agriculture together with an approach of building capacity of small farmers. TFT, also called Smart-farming, comprises four components, namely 1) soil series identification, 2) N-P-K testing by soil test kit, 3) fertilizer recommendations using decision-aids and a simplified version of a complex model and 4) farmer empowerment. The benefit of TFT at the rice field of the Huay Kamin chairman farmer group was one example, the technology has been disseminated to the 80 members with a total planting area of about 320 ha. The results revealed chemical fertilizer reduction of $69 \%$, and rice yield increased some $10 \%-20 \%$ with the improved fertilizer application method. The farmers were encouraged to establish "Soil Clinics" in their communities. In a Soil Clinic, designated and trained farmer leaders analyze soil samples for member farmers and provide TFT recommendations while providing access to fertilizer materials available for sale at competitive prices. At present, there are about 70 soil clinics in 20 provinces with the support of many government and private sectors.
\end{abstract}

\section{Keywords}

Empowering Farmer Leaders, Site-Specific Nutrient Management, Smart-Farming, Tailor-Made Fertilizer Technology, Soil Test Kit, Soil Clinic

\section{Introduction}

The current population of Thailand is 69 million with some 5.7 million farms 
with an average farm size of 3.15 ha. Agriculture is one of the major sources of the economy, wherein more than $60 \%$ of the total population is involved in agriculture.

Chemical fertilizers play a vital role in raising agricultural productivity. Their significance is even greater in view of the steadily declining amount of arable land suitable for agriculture, deteriorating soil quality, and strong competition in the global market for agricultural goods. The consumption of chemical fertilizers in Thailand increased from 2.3 million tons in 2000 to 5.0 million tons in 2015, which cost about USD 1835 million. Approximately 42\% of the fertilizer was used for 10.4 million ha of wet and dry season rice, of which $27 \%$ of the total rice land was used for irrigated rice in the dry season [1].

Due to the oil shock in 2008, the price of fertilizers greatly increased. As a consequence, the Thai Ministry of Agriculture and Cooperatives issued a policy to reduce the use of chemical fertilizers. The management of crop nutrients and fertilizers became very important, especially for economic reasons. The NPK fertilizer recommendations for most crops obtained from field experiments could not be transferred to other locations where the climate, soil type, crop variety, and management were different. The lack of self-awareness of farmers, combined with limited access to soil-testing laboratories and the lengthy delays of receiving recommendation resulted in blanket fertilizer recommendations-one size fits all-without soil testing for farmers' practices. The TFT technology directly counteracts that trend [2].

To ensure reduced production costs and increased crop yields in small farms, an effective and sustainable process for disseminating the Site-specific Nutrient Management technology, known in Thailand as the Tailor-made Fertilizer technology (TFT or Smart-Farming), through Soil Clinic was proposed. This paper reports on the nation-wide benefits from TFT in rice production, establishing Soil Clinics, and reports on the effective dissemination of TFT through Soil Clinics.

\section{Benefits from TFT in Rice Production}

The TFT for maize, rice and sugarcane in the Northeastern region was developed at Kasetsart University, Thailand, between 1997-2007, by adapting the concepts of precision agriculture together with building social and individual capacity of small farmers [2] [3]. TFT is the first adaptation of precision agriculture research work in Thailand and represents a model of adaptation of Precision Agriculture for small farms of the tropics.

TFT comprises four components, namely 1) soil series identification, 2) NPK testing by soil test kits, 3) precise fertilizer recommendation using decision-aids and complex models and 4) farmer empowerment [3].

We have introduced the technology to maize farmers for 18 years and to rice and sugarcane farmers for 13 years. The farmers who followed the technology have reduced their production costs and earned more profit compared to those 
farmers using the traditional, one-size-fits-all method of blanket fertilizer recommendations.

A representative example is Mr. Rom Wannaprasert, chairman of the Huay Kamin farmer group in Saraburi province in the Central Plain of Thailand. He and four members of that farmer group have used TFT for rice production since 2008. TFT reduced chemical fertilizer use by $40 \%$ while obtaining a $12 \%$ increase in yield. This occurred in the first crop year. It should be noted that Mr. Wannaprasert discontinued using insecticide and reduced costs by US\$ 73 per ha since 2010 (Table 1). The cost of chemical fertilizer use and yield in 2007 is shown with no TFT application for comparison.

From the obvious benefit of TFT on the rice fields of the Huay Kamin chairman farmer group, the technology has been disseminated to the 80 members with a total planting area of about 320 ha. The results revealed a reduction in chemical fertilizer use of $69 \%$, corresponding to fertilizer cost reduction from US\$ 51,757 in 2008 to US\$15,515 in 2015. Concurrent with the cost decrease was the increase in rice yield by some $10 \%-20 \%$ with the improved fertilizer application method.

\section{Establishment of Soil Clinics}

The technique of capacity building was employed to encourage farmers to become aware of TFT and learn how to use it. The technique results in continuous self-improvement, which is essential for farmers and their institutions in achieving a balance in economic, social, and environmental development goals. The main components of capacity building include farmer-centered development, participation of farmers, and a participatory learning forum or interactive learning [2].

Farmer-centered development means not only improvement in farmer's knowledge and capacity but also in their morale. TFT farmers assume a major role in decision making and managing their affairs while the GOs, NGOs and

Table 1. Fertilizer use and rice yields achieved by TFT started from 2008.

\begin{tabular}{ccc}
\hline Year & Fertilizer (US \$/ha) & Yield (ton/ha) \\
\hline 2007 & 243 & 4.69 \\
2008 & 145 & 5.25 \\
2009 & 99 & 5.19 \\
2010 & 94 & 5.25 \\
2011 & 105 & 5.44 \\
2012 & 134 & 4.69 \\
2013 & 88 & 5.94 \\
2014 & 66 & 5.63 \\
2015 & 60 & 6.06 \\
2016 & 72 & 5.75 \\
2017 & 72 & 7.00
\end{tabular}


those in the private sector have supporting roles in providing guidance, comments, advice, and training. Interactive learning through "learning by doing" enhances building capacity of farmers to control their lives and businesses.

One of the most powerful techniques of improving farmer knowledge is demonstrating and convincing the farmers that they have knowledge that is useful and, if they use it correctly, they can change some of the critical factors of production. Consequently, not only the knowledge of TFT was given, but also many problems and challenges in rice production, especially issues related to seeds, insects, diseases, soil improvement, and strategic planning, were discussed and solutions found by the farmers.

\section{Smart Problem Identification Technique in Crop Production}

Participation of farmers. Farmers are encouraged and stimulated to develop self-reliance, in this way the Smart technique is illustrated and recommended for farmers to learn to identify problems systematically in crop production. The technique recommends that farmers should focus not more than three major problems in a single cropping season. In a participatory learning forum, farmers learn to modify and adapt the package of knowledge themselves with our supervision. The integrated knowledge for crop production results in a slightly modified and adopted TFT.

Three steps of the Smart problem identification technique in crop production are taught, preferably by example and by doing rather than by only giving lectures on the concepts. The technique can be used subsequently for any problem solving. The steps include the following:

a) Assembling farmer leaders. Ten to fifteen farmer leaders of the farmer group are gathered in one place at the same time.

b) Setting the target and identifying major problems. The most common target issue is reducing the cost of crop production. The target should be clear, possible, and challenging. For example, a target might be: Reducing the cost of rice production by $15 \%$ in the next cropping season. The farmer leaders set the target individually for their next cropping season and no more than seven problems are identified at a time. Then, based on self-reliance, they select not more than three major problems with possible solutions and set priority of those problems. The target, problems and major problems are, consequently, noted in the table of eight slots on paper as shown in Table 2.

c) Brainstorming to summarize the target and major problems with some simple, practical solutions. This is an essential action step in technology transfer in the farmer group whereby theory, ideas, and local wisdom of the farmer leaders are integrated and put into practice.

\section{Guideline for the Establishment of Soil Clinics}

To improve access and adoption of TFT, we encouraged farmers to establish Soil 
Table 2. A working smart table of eight slots for problem identification.

\begin{tabular}{|c|c|}
\hline 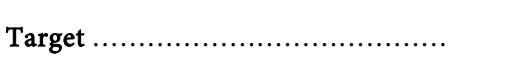 & $\begin{array}{l}\text { Problem } 1 \\
\text { (Selected) }\end{array}$ \\
\hline $\begin{array}{ll}\text { Problem } 2 & \ldots \ldots \ldots \ldots \ldots \ldots \ldots \ldots \ldots \ldots \ldots \ldots \ldots \\
\text { (Selected) } & \text { Major problem } 1\end{array}$ & Problem 3 ................................... \\
\hline Problem 4 .................................. & Problem 5 .................................. \\
\hline Problem $6 \ldots \ldots \ldots \ldots \ldots \ldots$ & $\begin{array}{l}\text { Problem } 7 \\
\text { (Selected) }\end{array}$ \\
\hline
\end{tabular}

Clinics in their communities in 2013 with the initial support of the Kyuma Fund. Soil Clinics are designed to be relatively low-tech and simple so that a group of farmers can develop and maintain their own. In a Soil Clinic, the designated and trained farmer leaders analyze soil samples for member farmers, provide the TFT recommendations and make fertilizer materials available for sale at competitive prices. Farmers, in turn, participate in group purchases of fertilizer at reduced cost.

The Soil Clinic was an innovation by which the problems associated with 1) fake, low-quality fertilizers 2) excessively high fertilizer prices and 3) incorrect fertilizer use could be solved by the local farmer leaders for farmers in their community.

Five steps are proposed for the establishment of Soil Clinics:

1) Selecting the area for establishing Soil Clinics. Soil Clinics often begin with rice because it is the most important economic crop in Thailand and farmers very frequently use excessive quantities of chemical fertilizers, especially for irrigated rice. Thus, the target area is typically focused at the sub-district with rice as the main crop and also there are farmer groups.

2) Identifying and locating famer leaders. About 10 to 15 successful farmer leaders in the sub-district are identified. Volunteer farmer leaders are selected and trained to be part of the Soil Clinic management team.

3) Capacity building of farmer leaders. In the process of interactive learning, we encourage farmer leaders to set targets for their crop production and identify the major problems with practical solutions by using the Smart problem identification technique. The farmer leaders are trained in the technique. The training can be considered empowering because it includes the following topics:

- Basic knowledge of soils, plant nutrients, fertilizers, and fertilizer use.

- Concept of and benefits from TFT.

- Sample collection for soil analysis.

- Soil analysis. The soil test kit is a simplification of the standard laboratory soil analysis. With training, the soil test kits enable the farmer leaders to measure soil $\mathrm{pH}$, nitrate and ammonium, phosphorus, and potassium in about $30 \mathrm{mi}-$ nutes (Figure 1).

- Soil series identification. Farmers don't need to understand the soil series classification in detail, but they need to know the name of soil series in their 


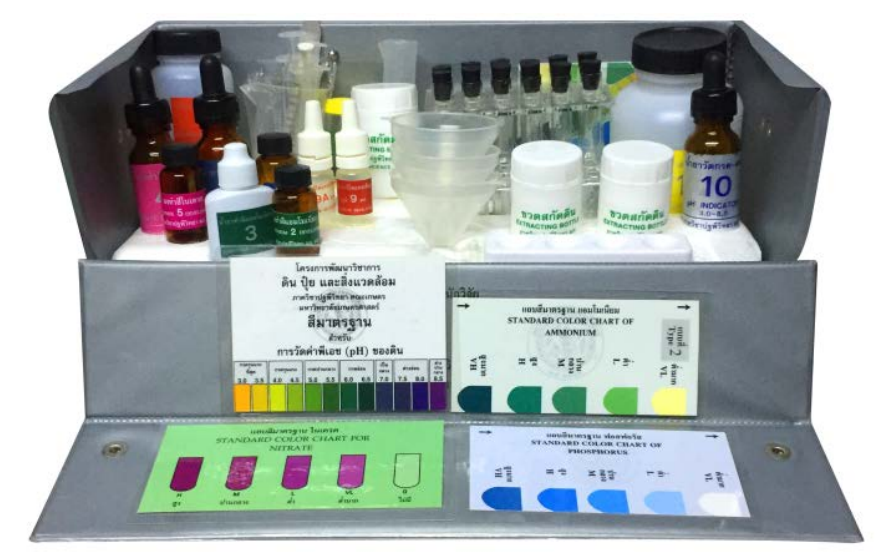

Figure 1. KU soil test kit.

farmland. In 2002 a practical handbook was developed for identifying soil series that enabled extension officers and farmer leaders to identify the soil series by themselves. Subsequently, the developed procedure was published [4]. It is sometimes more convenient to use existing soil series maps at sub-district level as a simple visual tool (Figure 2).

- In 2019, a TFT app was developed for soil series searching and fertilizer recommendation. Farmers use the app, find soil series of their fields, and input the soil test results, then fertilizer recommendation will be reported. When farmers add the cost of fertilizer, other costs of production, and the price of the commodities, the production benefit is estimated and shown to the user. (Figure 3).

4) Disseminating knowledge and information of TFT to farmers in the target area. The trained farmer leaders with effective tools of basic knowledge of soils and fertilizers, soil analysis by soil test kits, TFT app and Soil Clinics, facilitate the transfer of knowledge and information of TFT to farmers in their community.

5) Organizing TFT Service Day. A TFT Service Day follows closely to the principle of the Participatory Learning Forum. Our experience during 2013-2016, was that about $100-400$ farmers attended each event with $60 \%-70 \%$ of the farmers came with soil samples for analysis. Activities during the TFT Service Day include the following:

- Organizing a learning forum on the basic knowledge of soils, plant nutrients, fertilizers, fertilizer use as well as the concept of and benefits from TFT (Figure 4).

- Sharing experiences using TFT in rice production by farmer leaders. This activity is essential to convince farmers on the benefits of using TFT in reducing fertilizer use and increasing yield (Figure 5).

- Providing services in soil analysis by soil test kit and the Tailor-made Fertilizer recommendation by farmer leaders. We developed the process of soil analysis whereby two farmer leaders as a team can analyze about thirty soil samples within a period of three hours in the morning. While farmers are 

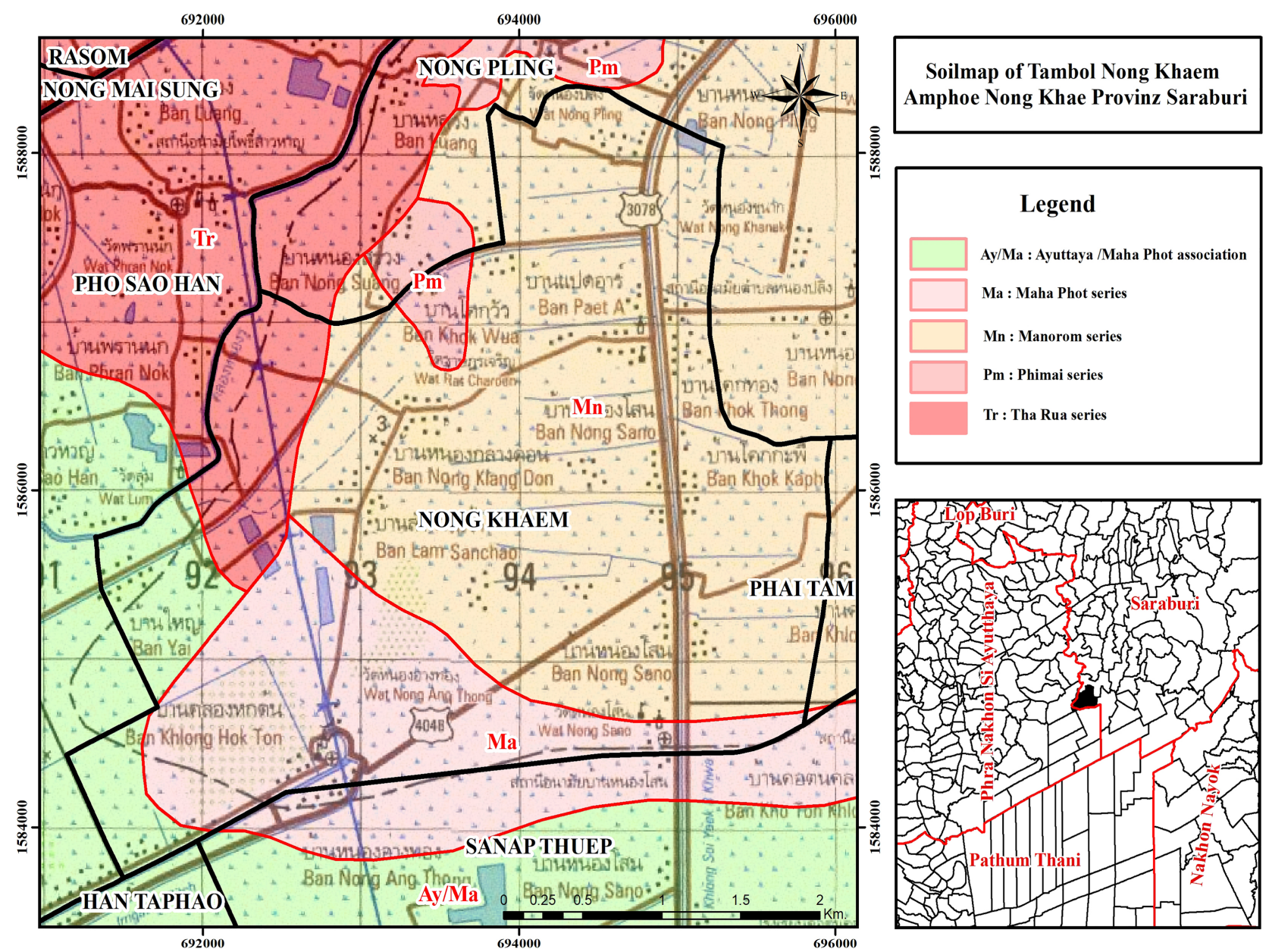

Figure 2. The soil series map of Nong Khaem sub-district, Nong Khae district, Saraburi province.

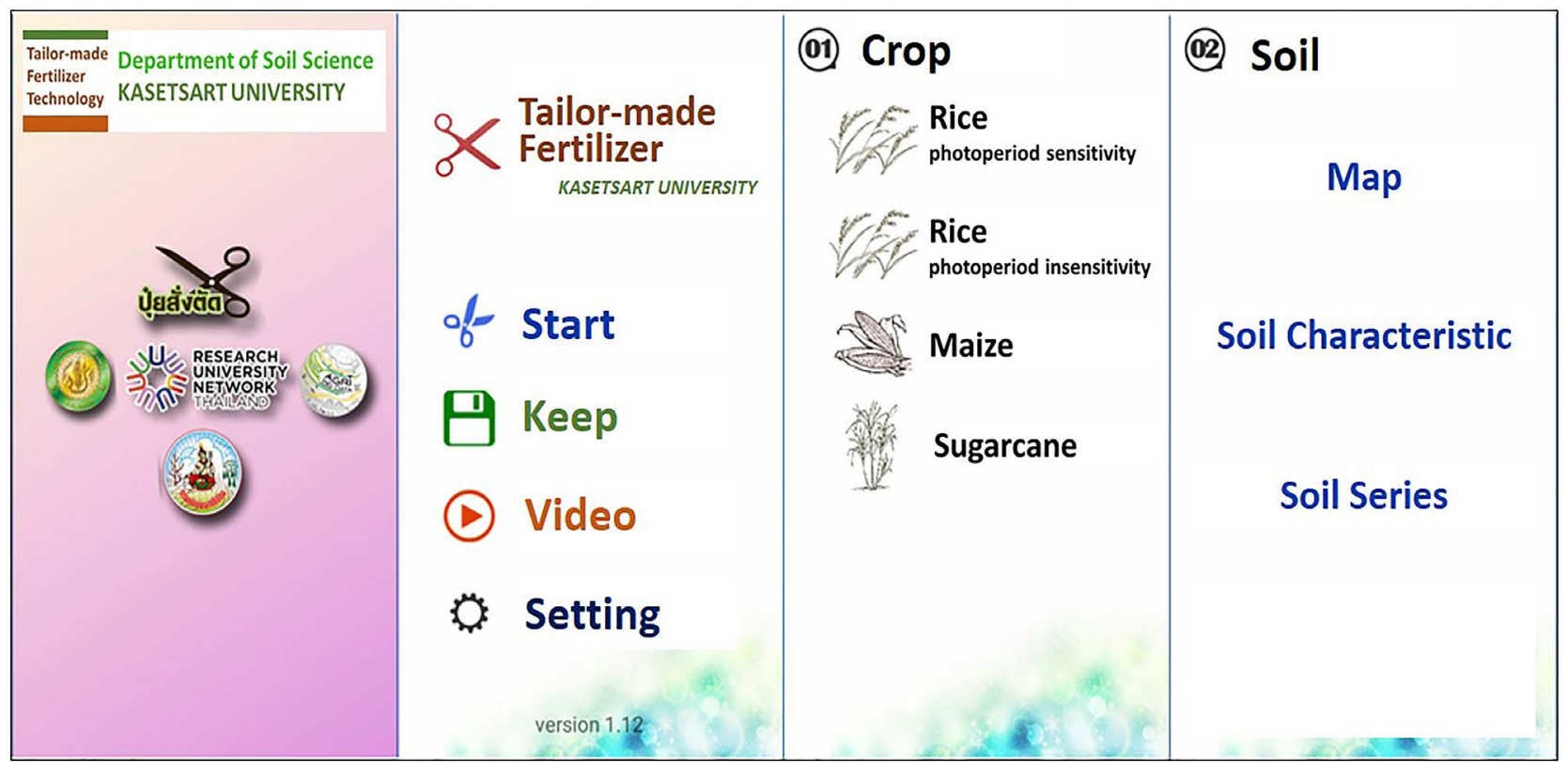

Figure 3. Tailor-made fertilizer technology application in the smart phone. 


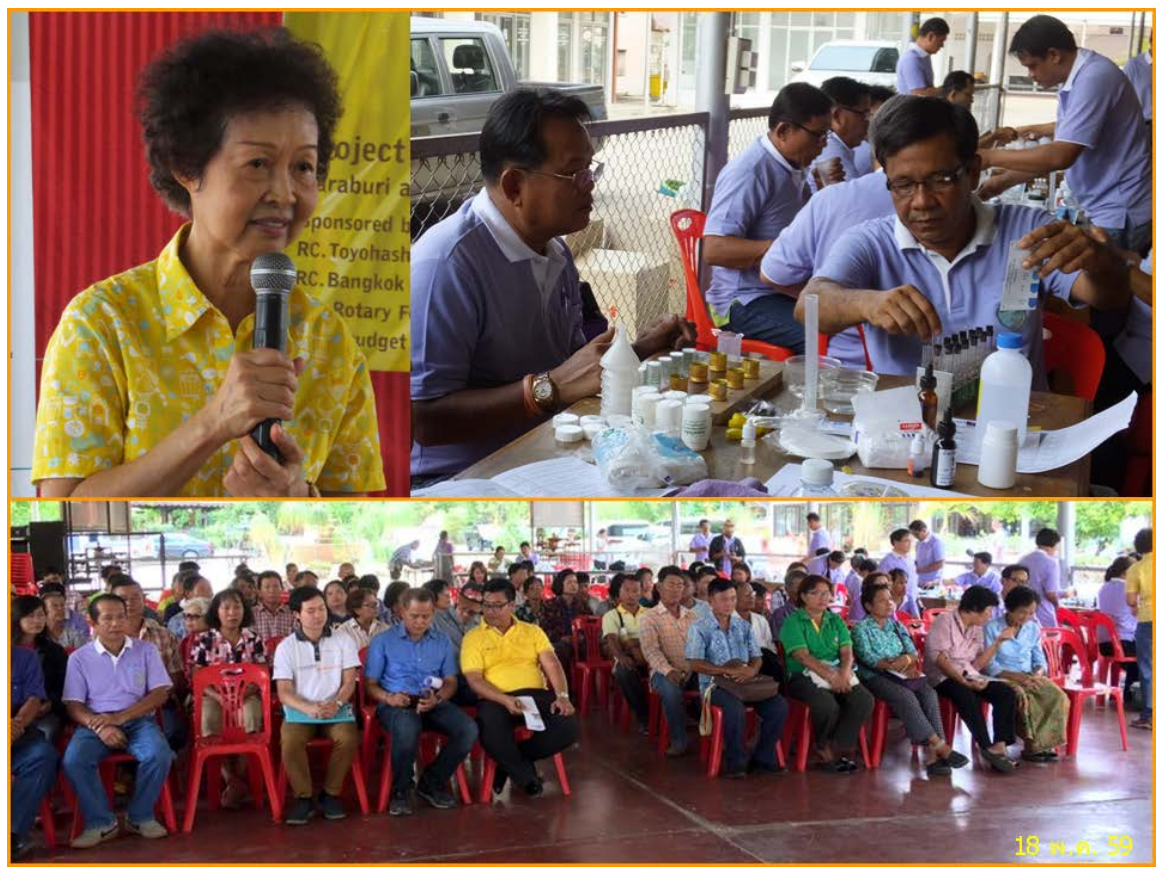

Figure 4. Learning forum of farmers on May 18, 2015.

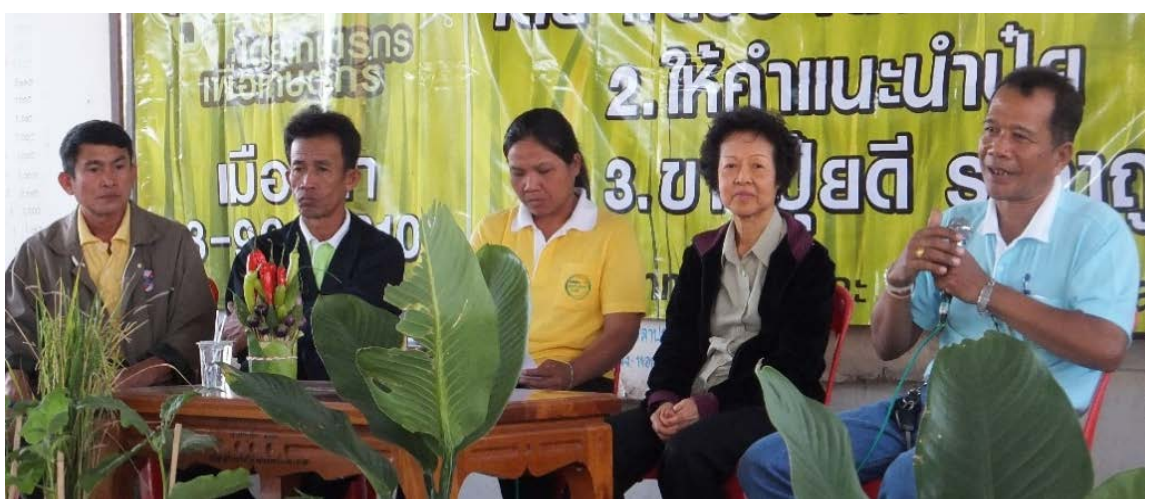

Figure 5. Farmer leaders sharing experiences from using TFT in rice production on January $18,2015$.

waiting for the results of soil analysis, they can attend a learning forum described above. Then, after lunch, the results of soil analysis with the fertilizer recommendation are presented and discussed with the farmers (Figure 6).

As of May 2019, farmer leaders have established a total of 70 Soil Clinics in 20 provinces with technical support from our working group and with financial support from the government and private sectors.

\section{Dissemination of TFT through Soil Clinics}

In 2007, Department of Agricultural Extension (DOAE) officially transferred TFT to farmers in the irrigated areas for rice production in Angthong, Chainat, Phra Nakhon Si Ayutthaya, and Nakhon Prathom provinces in the Central Plain. In recent years, TFT has thus been effectively disseminated through Soil Clinics 


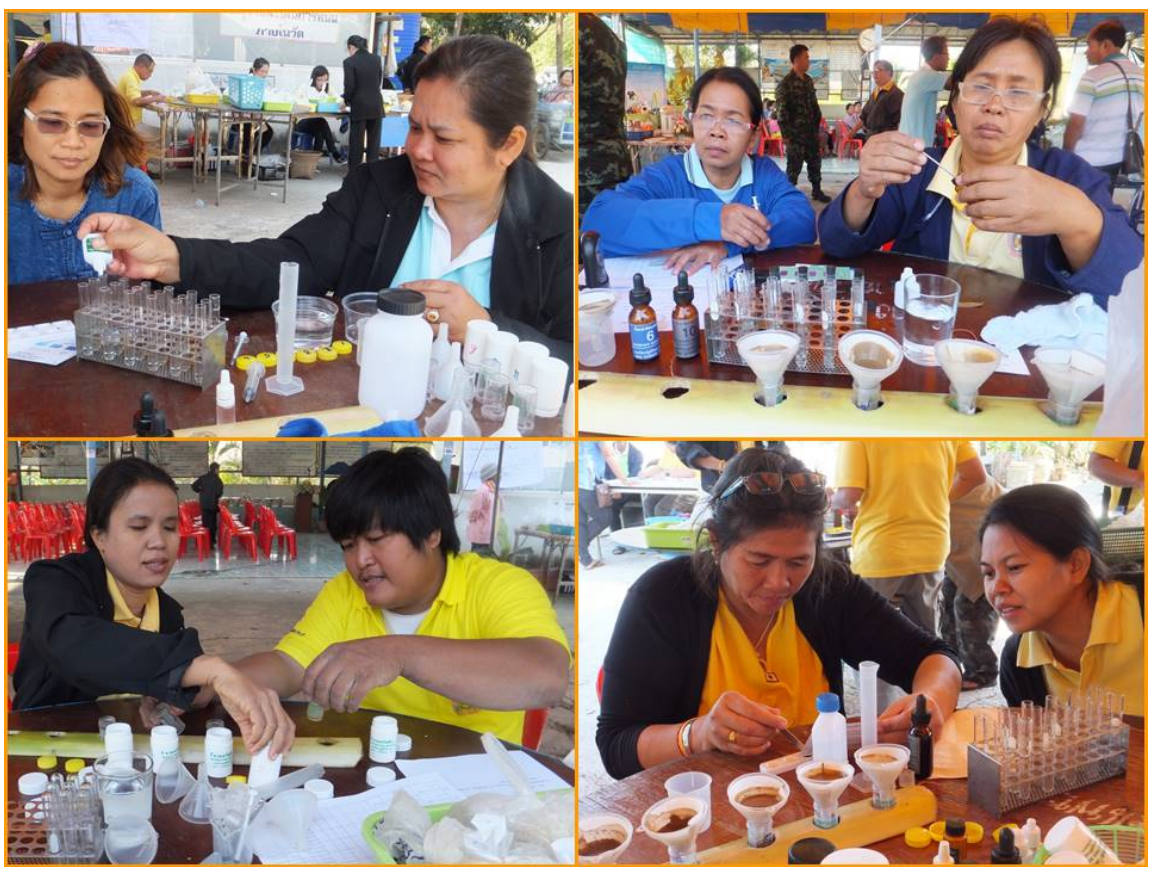

Figure 6. Soil analysis is provided to farmers by farmer leaders on January 18, 2015.

in the rice producing provinces.

In 2013, the first three Soil Clinics were established in Saraburi (Huay Kamin Soil Clinic) and Suphanburi provinces in the Central Plain, and Khon Kaen province in the Northeast Region. This initial effort was possible with the support of the Kyuma Fund (Prof. Dr. Kazutake Kyuma, Kyoto University, Japan).

In 2014, the Rotary Club of Bangkok Benjasiri supported the management team of Huay Kamin Soil Clinic to establish four Soil Clinics in Saraburi province. The leaders of those four Soil Clinics created a network named "Loom Chao Phraya Pasak" to organize the TFT Service Day for farmers in their community. The results of this farmer network were 20 demonstration plots with a total area of 41 ha in Ban Lam sub-district, Wiharn Daeng district. The TFT reduced chemical fertilizer use by $51 \%$, while the rice yield was increased $17 \%$.

During 2014-2015, National Research Council of Thailand (NRCT) supported the Loom Chao Phraya Pasak Network in establishing another sixteen Soil Clinics-five Soil Clinics in Saraburi province, five Soil Clinics in Phra Nakhon Si Ayutthaya province in the Central Plain, and six Soil Clinics in Chiang Rai province in the Northern Region. Every Soil Clinic organized the TFT Service Day for farmers in their community and nearby areas. There were a total of 3683 farmers with 3239 soil samples processed by the TFT at these events. In the crop year 2015, report from five farmers in each province revealed that TFT reduced chemical fertilizer use by $40 \%$ from 130 to 78 US $\$$ /ha with $14 \%$ increase in the rice yield from 4.71 to 5.38 ton/ha. Impressively the cost of insecticides decreased $79 \%$ from 95 to 20 US \$/ha. Another farmer network, namely Kok Ing Lao Loomnamkum was created in Chiang Rai province. 
In 2015, the Lions Club of Bangkok Dusit supported the Loom Chao Phraya Pasak Network to establish a Soil Clinic at Nong Sai Khao sub-district, Ban Mee district, Lop Buri province in the Central Plain.

In 2015, the Department of Agricultural Extension (DOAE) agreed to implement the Soil Clinic concept as a national policy by supporting up to 882 Soil Clinics in every district throughout the country. The benefits of Soil Clinic have been achieved from the first year for some economic crops such as rice, maize, cassava, rubber and oil palm. DOAE reported a reduction of $26 \%$ of chemical fertilizer use (a total of US\$ 1.15 million) while obtaining a remarkable $10 \%$ increase in crop yields from 2016 harvesting season. This involved 17,640 farmers with planting area of 17,490 ha [5].

During 2016-2017, the Rotary International, the Rotary Club of Toyohashi, Japan, and the Rotary Club of Bangkok Benjasiri supported the Loom Chao Phraya Pasak and the Kok Ing Lao Loomnamkum Networks to organize a TFT Service Day with a total of 18 events in Saraburi, Suphanburi and Chiang Rai provinces, and in Nakhon Ratchasima province in the Northeast Region. There were about 3241 farmers with 1638 soil samples for analysis at the events.

The Rachamongkol Rice Company Limited, an affiliation of Toyota Motor Thailand Corporation, supported farmer leaders in Plaeng Yao district, Chachoengsao province in the Eastern Region, and Phonsai Agricultural Cooperatives, Roiet province in the Northeast Region, to establish Soil Clinics in 2016 and 2017, respectively.

During 2017-2018, Kasetsart University Foundation supported farmer leader networks to establish 13 soil clinics in 4 provinces of rice production.

\section{Conclusions}

Thai farmers previously used the traditional one-size-fits-all method of blanket fertilizer application recommendations. The TFT-Smart-Farming for small-holder farmers has been developed and adapted from the concepts of precision agriculture since 1997, and can be considered as the first precision agriculture research work in Thailand. The conceptual approach of both simplifying the complex technology and empowering the farmers to learn the technology and to become self-reliant has been a distinctive, creative part of the TFT.

The simplified technology includes the process of soil analysis using soil test kits, employing soil series maps at the sub-district level, and developing a smartphone app for Tailor-made Fertilizer recommendations. For building capacity of farmer leaders, the Smart problem identification technique based on self-reliance was developed to encourage and enhance continuous improvement of the actual crop production technology.

The resulting precise fertilizer applications can result in more efficient and economic use of plant nutrients and yield increases resulting, in turn, with a mitigation of pollution caused by excess fertilizer application. Improved production, healthier products, increased capacity and health of farmers are, thus, achievable 
goals for better livelihoods of farmers. The results obtained during the past four years of 16 soil clinic establishment in 3 provinces using TFT revealed that chemical fertilizer use in rice production has dramatically decreased $40 \%-51 \%$ while the crop yield increased $14 \%-17 \%$ compared with the current practice of farmers.

To improve access and adoption of TFT, we have encouraged farmers to establish Soil Clinics in their communities since 2013 and trained farmer leaders to analyze soil samples for farmers, provide the precise fertilizer recommendations and have fertilizer materials for sale at competitive prices. Consequently, the Soil Clinics have helped to solve three problems, 1) fake, low-quality fertilizers, 2) excessively high fertilizer prices, and 3) incorrect fertilizer-use.

As of May 2019, farmer leaders have established a total of 70 Soil Clinics in 20 provinces of Thailand with technical support from our working groups and with financial support from the government and private sectors. In addition, DOAE has been supporting 882 Soil Clinics in every district throughout the country since 2015. We expect that the number of Soil Clinics will increase throughout the nation-wide network, so that chemical fertilizer use in Thailand will be reformed.

\section{Acknowledgements}

The authors would like to express their sincere thanks to Dr. Anan Phonphoem, Mr. Pisit Makpaisit, Faculty of Engineering, Kasetsart University for their assistance in the TFT application preparation. Thanks are also due to Mr. Attaya Phinchongsakuldit, Mr. Kitti Wongsang, Land Development Department and Mr. Warakorn Khamkaew, NECTEC for their assistance in arranging data and application preparation.

\section{Conflicts of Interest}

The authors declare no conflicts of interest regarding the publication of this paper.

\section{References}

[1] Office of Agricultural Economics (2016) Agricultural Statistics of Thailand.

[2] Attanandana, T., Yost, R. and Verapattananirund, P. (2007) Empowering Farmer Leaders to Acquire and Practice Site-Specific Nutrient Management Technology. Journal of Sustainable Agriculture, 30, 87-104. https://doi.org/10.1300/J064v30n01_08

[3] Attanandana, T., Verapattananirund, P. and Yost, R. (2008) Refining and Disseminating Site-Specific Nutrient Management Technology in Thailand. Agronomy for Sustainable Development, 28, 291-297. https://doi.org/10.1051/agro:2008006

[4] Boonsompopphan, B., Vearasilp, T., Yost, R.S. and Attanandana, T. (2008) Field Identification of Soil Series: Indexing and Retrieving Soil Information while Sharing Experience and Knowledge. Soil Science, 173, 736-744.

https://doi.org/10.1097/SS.0b013e31818939cf 
[5] Matichon Newspaper (Thailand) (2017) Department of Agricultural Extension Recommended Farmers Use Chemical Fertilizers Based on Soil Analysis to Reduce Production Cost and to Increase Crop Yield. January 6, 2017. 